\title{
Gender in higher education: the current landscape in the UK
}

\section{Judy Robertson}

The UK aspires to have a world-leading higher education system, striving both to provide high quality education to students from all over the world and conduct world leading research. It is also committed to ensuring that research has an economic or social impact, and that access to higher education is widened.

There are 164 universities in the UK in receipt of public funds, educating 2.28 million students, and employing 201,380 academic and 208,750 non-academic staff . The ambitions for the sector are reasonably well founded - currently 400,000 international students have chosen to study here and in terms of research, the $4.1 \%$ of the world's researchers based in the UK produce $16 \%$ of the world's most highly cited articles.

Higher education in this country, however, is subject to a set of complex political and economic pressures which impact the working lives of staff and impact students. Life in the ivory tower is not altogether peaceful and productive. Furthermore, on peering through the windows of the ivory tower, we do not see equal proportions of men and women on each floor. The structure was built with glass ceilings, glass basements and all manner of other architectural barriers for women. 


\section{University students}

More women than men study at UK universities; there is a $12 \%$ gap in favour of women (up to $15 \%$ in Scotland, the part of the UK in which the University of Edinburgh is based). The proportion of women students varies by discipline, from as low as $17 \%$ women on engineering and technologybased courses to $81 \%$ women in subjects allied to medicine ${ }^{2}$. There is also a slightly higher proportion of men who are unable to continue with their studies. Women also perform better in terms of their final degree outcomes - in every subject (apart from social studies) women achieve a higher proportion of first class and 2:1 degrees. It is heartening that women are no longer in the minority at universities, although the widened gap does give some concern for the educational chances of men from disadvantaged backgrounds ${ }^{3}$ (see Educated Pass: engaging young males from low socioeconomic status backgrounds with learning).

Education really does enable women to improve their financial circumstances. Women graduates earn up to three times the income of women without degrees whereas graduate men earn twice the salary of male non-graduates 4 . The gender difference in the graduate premium is mostly because non-graduate wages for women are so low.

According to the Equal Pay Act 1970 and the Equality Act 2010, it is illegal to discriminate against people for their sex, race or other protected characteristics 5 . Despite this, there is an $18 \%$ gender pay gap in the UK which the government is leisurely committed to eliminating in a generation ${ }^{6}$. After all, as women have been waiting for pay equality for hundreds of years, what does a few decades matter? The government attributes the gender pay gap to a complex set of overlapping factors including the fact that women are less likely to progress up the career ladder, that more women work part-time and that "a higher proportion of women choose occupations that offer less financial reward (e.g. administration). Many high paying sectors are disproportionately made up of male workers (e.g. information and communications technology)." However, data suggests that even within jobs in the same sector, women are under-rewarded.

Analysis of the government's Longitudinal Earnings Outcome data 7 tells us that while education helps women gain prosperity, there is still a troubling gender pay gap which begins after graduation and continues to grow ${ }^{8}$. For example, the median difference in pay between male and female computer science graduates is already $£ 4,400$ five years after leaving university. So although it is true that there are proportionally fewer women (14\%) employed in the technology sector, women who are employed there are under-compensated. Gaps exist even in professions which have been traditionally female dominated such as education and nursing. There are further inequalities relating to intersectionalities; Pakistani, Bangladeshi, and Black Caribbean women graduates earn less than white women graduates. Universities, it would appear, have some work to do in helping their women students prepare to take their place in the financially unfair world of work (see Salary negotiation). Employers have even more work to do to ensure that they they are treating their female employees equitably.

University is not just a place to get a degree and then arrange a job. It is a place to learn, to make friends, to seek new experiences, to live. Unfortunately, studies suggest that women students can experience an unpleasant and harassing environment at university. In an online survey of 2,156 university students conducted by the National Union of Students $9,25 \%$ of students overall (and $37 \%$ of the women in the sample) had suffered unwelcome sexual advances, including inappropriate touching and groping. The same proportion had endured sexual comments about their body, and one-third had been made uncomfortable by overtly sexual conversations about them. About 30\% of respondents had experienced verbal harassment, and twothirds had heard jokes about rape when on campus. Two-thirds of respondents 
had witnessed fellow students experience sexual comments and conversations. The National Union of Students found in a later study that new students in their first week at university were particularly at risk, but that $61 \%$ of them were unsure how to report the incidents to their university ${ }^{10}$.

Such figures reflect the experiences of women in the wider public in the UK, where $64 \%$ of women have experienced unwelcome sexual attention and $35 \%$ have endured unwanted touching ". It would also seem that students report a good environment on university campuses (5.8 on a 7-point scale, slightly higher than in the community as a whole ${ }^{12}$ ). The harassment seems to be largely student to student, and in social or sporting places rather than within the classroom. The incidence and extent of staff-student harassment is not yet well documented.

A taskforce led by Universities UK has issued a set of recommendations about how universities can deal with sexual harassment ${ }^{13}$, calling for institutions to work closely with their student unions to "take an institution-wide approach to tackling violence against women, harassment and hate crime". An account of the University of Edinburgh's work relating to sexual harassment in partnership with the Edinburgh University Students' Union can be found later in the book.

Women students are likely to have witnessed or experienced harassment at some point during their studies, and may often experience conversations in which women are objectified or denigrated, or their personal appearance is scrutinised. Furthermore, women students are more likely to report mental health problems than men (34\% of women students, $19 \%$ of male students) ${ }^{14}$, including anxiety, depression and eating disorders. LGBT students are also disproportionately likely to suffer from mental health difficulties. The article about the Unapologetically Me project led by the Edinburgh University Students' Association gives some insight into what it is like to be a female or transgender person at university today.
There is much to be done to support all of our students to have positive experiences of universities. We want men to have opportunities to study and succeed at university, regardless of their socioeconomic background. We want women's academic excellence to be rewarded with job opportunities with equal chances of promotion and fair pay. We want all students to have positive mental health, and no one to experience harassment on campus or in wider communities. This must be accomplished in society as a whole, but universities can lead the way through educating graduates to be agents of change and by creating positive environments for learning (see Creating a safe space for classroom discussions).

\section{University staff}

Although the majority of staff in higher education institutions in the UK are women (44.6\% of academic staff), they are overrepresented in lower pay grades and underrepresented in higher pay grades 15 . For example, women are considerably less likely to be promoted to professor than men (only $23 \%$ of professors are women ${ }^{16}$ ), and only $20 \%$ of university principals are women. Women are also more likely to work part-time: $76.0 \%$ of men employed by universities work full-time compared with $58.3 \%$ of women. In terms of job security, a lower proportion of women are on openended contracts (61.5\% compared to $66.5 \%$ ).

Although universities in the UK use a jointly negotiated pay scale across institutions, a pay gap still exists in the sector. The gap is primarily caused by the lower proportions of women in senior grades (where the salary scale has more flexibility for discretionary increments), and is worse in elite institutions. The gender pay gap in universities currently stands at $12 \%{ }^{17}$, which is less than the pay gap across all sectors in the UK (18\%).

University staff in the UK are under pressure. In a 2014 study conducted by the UCU (University and College Union), 79\% of the 6439 respondents agreed or strongly

11 EqualBITE Gender in higher education: the current landscape in the UK 
agreed that they find their job stressful ${ }^{18}$. Academics are not alone in suffering from stress - the Health and Safety Executive calculate that stress accounts for $45 \%$ of working days lost due to ill-health across the UK ${ }^{19}$. Public service industries including education tend to have higher levels of stress. In fact, UCU members reported lower levels of well-being than average across all sectors in the Health and Safety Executive's stressor categories ${ }^{20}$. The Health and Safety Executive data also shows that more women than men suffer from stress across a wide age range, across the workforce.

High workload is one factor associated with stress at universities. In the UCU survey, more than a quarter of respondents found their workload unmanageable all or most of the time. Two-thirds found their workloads unmanageable at least half of the time. This is in spite of working long hours: $41 \%$ of people on full-time contracts reported working in excess of 50 hours per week (although standard contracts specify working hours in the range of 35-40 hour week), and one in ten report working 60 hours or more per week. According to the UCU, staff in higher education and FE are working an average of more than two days unpaid every week, with professors (56.1 hours), principal research fellows (55.7 hours) and teaching assistants ( 54.9 hours) reporting the highest average full-time hours per week. There is not a gender difference in working hours for staff on full time contracts, but women who work part-time with small fractions (one to two days per week) tend to work longer unpaid additional hours than men in the same position.

This is why it is particularly important for managers to ensure that the workload for staff on part-time or flexible contracts is carefully planned and managed (see Flexible working: being realistic). In response to the findings of these and similar surveys, the University and College Union and the National Union of Students have produced a joint statement ${ }^{21}$ calling on university employers to monitor staff workload to ensure that staff are not overloaded and unable to spend sufficient time with students to offer high quality education.

The UCU data from successive surveys confirms that academics are now working in a rapidly changing work environment, with expanded roles and greater administrative responsibilities. There are two major, potentially contradictory, demands on staff in the form of the Research Excellence Framework (REF) and now the Teaching Excellence Framework (TEF). (It is worth noting that many Scottish universities, including Edinburgh, opted out of the TEF 22 on the grounds that there is already an effective way of reviewing and enhancing HE (higher education) teaching in Scotland). Universities must invest considerable time and attention to ensuring high standards in these areas because they both have large funding and reputation implications. Many universities are trying to wrestle with the demands of maintaining research and teaching excellence, which is difficult to achieve as the success of both enterprises commonly rely on the efforts of the same individuals. "How can I keep my research going and still do my best teaching?" is surely a familiar refrain for academics the world over but it is brought to an excruciating head by the relentlessly high standards and exacting data gathering of the excellence frameworks. Factor in a highly competitive environment both between staff and between institutions, and it is no wonder that stress levels among academics are so high, workplace satisfaction has plummeted, and reports of personal harassment and bullying have increased ${ }^{23}$.

There is reason to believe that women are more vulnerable to such HE workplace pressures because of widespread unconscious bias. With respect to research, studies of the REF indicate that women were less likely than their male colleagues to have work submitted to the REF ${ }^{24}$ (51\% of the available pool of women compared to $67 \%$ of the available pool of men had their work submitted for review), which has the potential to damage morale and promotion prospects for women. (See Emily 
Yarrow's Gender and the Research Excellence Framework for an in-depth consideration of this.) Furthermore, evidence is mounting internationally and across disciplines that because of implicit bias, women academics are less likely to receive invitations to review papers (Lerback, 2017), are invited to speak at conferences less frequently (Nature, 2016), and have lower grant success rates (RCUK, 2016). These topics are tackled in more depth in Gender balancing your scholarly journal, Gender balancing your seminar speakers and How to become a better scientific evaluator. Again, being subject to the steady "drip drip" of unconscious bias has an impact on career progression and self-efficacy (see Dealing with imposter syndrome). Moreover, when teaching is evaluated by student satisfaction scores (which is one measure used in TEF), women will potentially be disadvantaged due to unconscious bias of (male) students against female teachers (Boring, 2017; MacNell, et al., 2014).

In summary, there are persistent gender inequalities in UK higher education. Women staff are less likely to be promoted to higher grades, are less likely to have permanent contracts, and are paid less. Women in general are also more likely to suffer from workplace stress, and it is known that the $\mathrm{HE}$ sector in the UK is a particularly stressful place to work at the moment. Two of the major factors which contribute to workload and stress in $\mathrm{HE}$ - measurements of research and teaching excellence-can perpetuate gender inequalities through implicit bias.

\section{Athena SWAN}

In spite of the the bleak picture of higher education in the UK, there is good reason to be cheerful: Athena SWAN ${ }^{25}$. This charter, started in 2005 by the Equality Challenge Unit, aims to remove barriers to progression and success for all. The scheme started with a focus on the experiences of women students and academic staff in the STEMM disciplines (science, technology, engineering, medicine and mathematics), but since 2015 has been expanded to include arts, humanities, social sciences, business and law (AHSSBL) as well as professional services and support staff. It now considers the perspectives of men (where appropriate) and also trans people. The scheme has been extended to include the Republic of Ireland, and a similar scheme is under consideration in Australia ${ }^{26}$. By its tenth anniversary, 143 institutions had joined Athena SWAN, holding 669 awards between them. In applying for an award, departments must show quantitative evidence relating to the representation of women, the progression of students into academia, career progression and working environment. Since 2015, the charter has also committed to tackling the gender pay gap, addressing the consequences of short-term contracts on career progression, tackling discriminatory treatment against trans people, and to using an approach of intersectionality to consider individuals whose experiences are shaped by the intersection of gender and race, and other protected characteristics.

Athena SWAN awards are hard won. Higher education institutions in the UK can apply for Athena SWAN awards at Bronze, Silver or Gold level, as can individual departments within each institution. For a Bronze award, the department must show evidence of a solid foundation towards dismantling discrimination and fostering an inclusive culture. Silver award holders have a significant record in promoting and achieving equality. To achieve Gold, there must be sustained progress, and the responsibility to be a beacon of achievement, and a champion of good practice to other institutions. Bronze applications have a success rate of $64 \%$, new Silver awards are $33 \%$ successful, upgrades from Bronze to Silver applications are 50\% successful and Gold awards are only 33\% successful. The awards must be renewed regularly, and the success of the Athena SWAN charter in terms of meeting its aims is also subject to review and evaluation.

An evaluation of the Athena SWAN scheme in 2013 (Fox, 2014). found evidence of sustainable culture and attitude changes within the award-holding departments. While the report indicated further work is needed in supporting undergraduate and postgraduate students, and that the process of preparing for a submission was considered by some to be burdensome, there was considerable evidence that Athena 
SWAN is a valuable driver for improving gender diversity (MacNell, et al., 2014). Staff who work in a department which "lives the Athena SWAN life" appear to be more satisfied with their work environment.

It is possible to argue that Athena SWAN can be a mechanical box-ticking exercise but in a sense, it does not matter if this is how it starts: models of behavioural change indicate that external motivation can be a driver for internalising change (see A model for change). As the Pro Vice Chancellor of Cambridge University put it:

"Athena SWAN provides a stimulus because universities and their staff are competitive; they like recognition and prizes. It gives us a framework to help improve processes and behaviours, and it is also a good mechanism for sharing expertise and good practice" ${ }^{27}$. What matters is that the Athena SWAN awards are a true reflection of the institutional culture rather than a metallic veneer over deep-rooted inequalities. A recently published evaluation of the working culture of a well-known UK university which holds an institutional Silver award ${ }^{28}$, illustrates that this might not always be the case. Researchers external to the university, using a qualitative action inquiry approach, found that the institutional culture of individualised excellence in research was to the detriment of the well-being of staff and students and many examples of bullying and discrimination were described. It is vital that the Equality Challenge Unit considers this sort of contradiction as part of its ongoing self-evaluation. Documenting staff satisfaction is one way to approach this.

Athena SWAN has created and responded to pressures from the wider research infrastructure in the UK. In 2011, the Department of Health linked some future National Institute for Health Research funding to achievement of an Athena SWAN silver award, resulting in a healthy (and probably hasty) increase in applications from medical and dental schools ${ }^{29}$. Research Councils UK (RCUK) has stopped short of requiring Athena SWAN accreditation ${ }^{30}$ but have muttered darkly about requiring it in the future "if there is no evidence of improvement". RCUK are no doubt focusing their energies on improving their own woeful equality track record RCUK (2016). For their part, Athena SWAN will now require departments to consider RCUK data on success rates as part of departmental Athena SWAN submissions. If giving out shiny metal badges for success is a good carrot for competitive academics, threatening to cut off research funding is an excellent motivational stick. A cynic might suggest these tactics are what will really make gender equality more than "a ladies' problem".

\section{Conclusion}

The ivory tower, like other stately homes in the UK, might present a grand façade to the world but closer inspection reveals a dark, spidery basement full of inequalities. Men from disadvantaged social backgrounds might never make it to the ivory tower in the first place, and men who do get there are less likely to do well. Women students are more likely than men to suffer from mental health problems and encounter sexual harassment during their university lives, and even as graduates will earn less pay for the work they do during the course of their careers. Women staff are less likely to have permanent contracts, and considerably fewer of them ascend the career staircase of the ivory tower to professorial or senior management levels. Those who do make it there are paid less than men. The occupants of the ivory tower no longer sip port and think deep thoughts. Instead they drink Red Bull and fill in spreadsheets. They work long hours under stress to serve conflicting, crushing governmental agendas of excellence.

Yet, being an academic is still a privilege. It is a joy to teach and learn from young minds, and to draw on the wisdom and experience of colleagues. Academia offers an unparalleled opportunity to think and generate knowledge (in between completing spreadsheets). It is also our chance to persuade each of our graduates to go out and tackle inequalities wherever they find them. Change may happen slowly, but Athena SWAN is surely making it happen. Every Athena SWAN award is a little candle in a window of the ivory tower. 


\section{Online references}

' http://www.universitiesuk.ac.uk/facts-and-stats/ Pages/higher-education-data.aspx

${ }^{2}$ http://www.ecu.ac.uk/wp-content/ uploads/2015/11/Equality-in-HE-statistical-report2015-part-2-students.pdf

3 http://www.hepi.ac.uk/wp-content/ uploads/2016/05/Boys-to-Men.pdf

${ }^{4}$ https://www.ifs.org.uk/publications/7998

5 https://www.gov.uk/discrimination-your-rights/ types-of-discrimination

\section{${ }^{6}$ https://www.gov.uk/government/news/uk- gender-pay-gap}

7 https://www.gov.uk/government/statistics/ graduate-outcomes-longitudinal-educationoutcomes-leo-data

${ }^{8} \mathrm{http}: / /$ wonkhe.com/blogs/why-is-there-such-alarge-gender-pay-gap-for-graduates/

9 https://www.nus.org.uk/Global/20140911 Lad Culture FINAL.pdf

${ }^{10} \mathrm{https} / / /$ www.nus.org.uk/en/news/two-thirdsof-freshers-not-aware-of-sexual-harrassmentreporting-procedures-at-university/

"http://www.universitiesuk.ac.uk/policy-andanalysis/reports/Documents/2016/changing-theculture.pdf

${ }^{12}$ https://www.timeshighereducation.com/news/ times-higher-education-student-experiencesurvey-2015-results/2019564.article

${ }^{13} \mathrm{http}: / /$ www.universitiesuk.ac.uk/policy-andanalysis/reports/Documents/2016/changing-theculture.pdf

${ }^{14} \mathrm{https}$ //yougov.co.uk/news/2016/o8/og/quarterbritains-students-are-afflicted-mental-hea/

$15 \mathrm{http}: / /$ www.ecu.ac.uk/wp-content/ uploads/2015/11/Equality-in-HE-statistical-report2015-part-1-staff.pdf

${ }^{16}$ https://www.ucu.org.uk/media/7959/ Holding-down-womens-pay-Feb-16/pdf/ucu_ IWDpayreport_mar16.pdf
${ }^{17}$ https://www.ucu.org.uk/media/8620/ The-gender-pay-gap-in-higher-education201516---full-report-May-17/pdf/ucu_201516genderpaygapreort_full_may17.pdf

${ }^{18} \mathrm{https} / / /$ www.ucu.org.uk/media/6908/UCUsurvey-of-work-related-stress-2014---summaryof-findings-Nov-14/pdf/ucu_stresssurvey14_ summary.pdf

${ }^{19} \mathrm{http}: / /$ www.hse.gov.uk/statistics/causdis/stress/ index.htm

${ }^{20}$ https://www.ucu.org.uk/media/6908/UCUsurvey-of-work-related-stress-2014---summaryof-findings-Nov-14/pdf/ucu_stresssurvey14_ summary.pdf

${ }^{21}$ http://workload.web.ucu.org.uk/jointstatement/

${ }^{22} \mathrm{http}: / /$ www.ed.ac.uk/news/students/2017/ teaching-excellence-framework

${ }^{23}$ https://www.ucu.org.uk/media/8196/

Executive-summary---Workload-is-an-educationissue-UCU-workload-survey-report-2016/pdf/ ucu_workloadsurvey_summary_jun16.pdf

24 http://www.hefce.ac.uk/news/ newsarchive/2015/Name,104986,en.html

${ }^{25} \mathrm{http}: / /$ www.ecu.ac.uk/equality-charters/athenaswan/

${ }^{26} \mathrm{http}: / /$ www.ecu.ac.uk/wp-content/ uploads/2015/10/AS_10th-Anniversary-BookletFINAL.pdf

${ }^{27} \mathrm{http}: / /$ www.ecu.ac.uk/wp-content/ uploads/2015/10/AS_10th-Anniversary-BookletFINAL.pdf

${ }^{28} \mathrm{https}$ ://www.imperial.ac.uk/media/imperialcollege/staff/public/Institutional-culture-andgender-equality.pdf

29 http://www.ecu.ac.uk/wp-content/ uploads/2015/10/AS_10th-Anniversary-BookletFINAL.pdf

${ }^{30} \mathrm{http}: / /$ www.rcuk.ac.uk/media/news/120117/ 